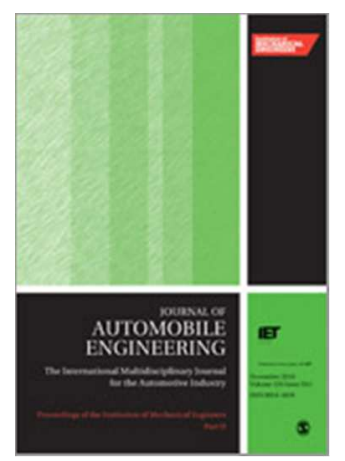

\title{
INVESTIGATION OF VEHICLE RIDE HEIGHT AND DIFFUSER RAMP ANGLE ON DOWNFORCE AND EFFICIENCY
}

\begin{tabular}{|c|c|}
\hline Journal: & Part D: Journal of Automobile Engineering \\
\hline Manuscript ID & JAUTO-16-0382.R1 \\
\hline Manuscript Type: & Original Article \\
\hline Date Submitted by the Author: & 26-Jan-2018 \\
\hline Complete List of Authors: & $\begin{array}{l}\text { knight, jason; University of Portsmouth, } \\
\text { spicak, milan; Vysoke uceni technicke v Brne Fakulta strojniho inzenyrstvi } \\
\text { Kuzenko, Antons; University of Hertfordshire, school of Engineering } \\
\text { Haritos, George; University of Hertfordshire, school of Engineering } \\
\text { Ren, Guogang; University of Hertfordshire, school of Engineering }\end{array}$ \\
\hline Keywords: & $\begin{array}{l}\text { vehicle aerodynamics, vehicle simulation/ modelling, alternative vehicle } \\
\text { designs, automotive components, Fuel efficiency/ economy, diffuser, } \\
\text { downforce, ahmed }\end{array}$ \\
\hline Abstract: & $\begin{array}{l}\text { Diffusers are typically used in motorsport to generate negative lift } \\
\text { (downforce). They also reduce aerodynamic drag and so significantly } \\
\text { enhance aerodynamic efficiency. The amount of downforce generated is } \\
\text { dependent on ride height, diffuser ramp angle and its relative length to } \\
\text { that of the vehicle length. This paper details a numerical investigation of } \\
\text { the effects of ride height and diffuser ramp angle in order to find an } \\
\text { optimum downforce and efficiency for the inverted Ahmed model. A short } \\
\text { and long diffuser with ratios of } 10 \% \text { and } 35 \% \text { respectively to that of } \\
\text { vehicle length are studied. The short diffuser produced lower maximum } \\
\text { downforce and efficiency at a lower ride height and lower angle when } \\
\text { compared to the longer diffuser. The long diffuser produced highest } \\
\text { downforce and the best efficiency with a ramp angle of } 25 \text { degrees at ride } \\
\text { height ratio of } 3.8 \% \text { when compared to vehicle length. Different ride } \\
\text { heights were found to correspond to different diffuser ramp angles to } \\
\text { achieve optimum downforce and efficiencies. }\end{array}$ \\
\hline
\end{tabular}




\title{
INVESTIGATION OF VEHICLE RIDE HEIGHT AND DIFFUSER RAMP ANGLE ON DOWNFORCE AND EFFICIENCY
}

\author{
Jason Knight ${ }^{1}$, Milan Spicak ${ }^{2}$, Antons Kuzenko ${ }^{3}$, George Haritos ${ }^{3}$, Guogang Ren ${ }^{3}$ \\ ${ }^{1}$ University of Portsmouth, Anglesea Road, Portsmouth, PO1 3DJ, UK \\ ${ }^{2}$ Brno University of Technology, Antonínská 548/1, 60190 Brno, Czech Republic \\ ${ }^{3}$ University of Hertfordshire, College Ln, Hatfield AL10 9AB, UK \\ ${ }^{1}$ Email: jason.knight@port.ac.uk (corresponding author)
}

\begin{abstract}
Diffusers are typically used in motorsport to generate negative lift (downforce). They also reduce aerodynamic drag and so significantly enhance aerodynamic efficiency. The amount of downforce generated is dependent on ride height, diffuser ramp angle and its relative length to that of the vehicle length. This paper details a numerical investigation of the effects of ride height and diffuser ramp angle in order to find an optimum downforce and efficiency for the inverted Ahmed model. A short and long diffuser with ratios of $10 \%$ and $35 \%$ respectively to that of vehicle length are studied. The short diffuser produced lower maximum downforce and efficiency at a lower ride height and lower angle when compared to the longer diffuser. The long diffuser produced highest downforce and the best efficiency with a ramp angle of 25 degrees at ride height ratio of $3.8 \%$ when compared to vehicle length. Different ride heights were found to correspond to different diffuser ramp angles to achieve optimum downforce and efficiencies.
\end{abstract}

Keywords: Downforce, Diffuser, CFD, Efficiency, Optimisation, Ahmed. 


\section{Introduction}

Aerodynamic component parts are commonly used in motorsport for generating downforce which leads to more traction force around corners. ${ }^{1}$ This can lead to achieving shorter lap times on high downforce circuits. One such component is the diffuser which is mounted underneath the car at the tail near the rear axle. In addition to increasing downforce, diffusers also reduce drag thereby significantly increasing aerodynamic efficiency of the race car. ${ }^{2}$ Like other extracomponents in racing cars, diffusers are also increasingly being used on production vehicles to reduce aerodynamic drag. ${ }^{3}$ Various materials including metals, metal bonded glass composites have been used to improve the aerodynamic efficiency by reducing skin friction drag on racing cars. ${ }^{4}$ More recently, advanced lightweight materials such as carbon fibre composites and ecofriendly natural fibre composites are starting to be used in varieties of car exterior body parts to investigate the possibility to cope with the large aerodynamic forces experienced whilst keeping the weight down and considering sustainability. ${ }^{5-7}$

Theoretically the main principle of generating down force with the diffuser is from the Venturi effect. $^{8,9}$ The significance of this effect is related to the change of the cross-section area of flow underneath the car at the start and end of the diffuser. The diffuser angle has a large influence on the rate of change of those areas. ${ }^{10}$ The ride height has a large influence on the cross section area at the start of the diffuser. ${ }^{11}$

Many studies have been performed using the Ahmed model in standard configuration with slanted edge uppermost. ${ }^{12-14}$ Tunay $^{15}$ performed wind tunnel tests using PIV for flow 
visualisation and matched this with CFD studies using LES turbulence model. ${ }^{16}$ Other LES studies using the Ahmed model have been performed. ${ }^{17-19}$ These works have captured the flow physics for use in analysing wake characteristics with aim of reducing drag.

The same Ahmed model has been inverted and used by Senior ${ }^{20}$ so that the slanted surface is closest to the ground to represent the diffuser of a simplified vehicle. Puglisevich ${ }^{21}$ has used the same approach with LES turbulence model. Senior ${ }^{20}$ varied the ride height and studied the effect of separation in the diffuser with resulting losses in downforce. Ruhrman ${ }^{22}$ has extended this work to investigate the ride height and ramp angle using a matrix approach. Humunic ${ }^{23}$ has also used this approach to study various lengths of diffuser combined with various ramp angles.

Other multi-parameter optimisations of automotive shapes have been studied by Han. ${ }^{24,25}$ They investigated various upper-surface backlight angles with various boatailing angles at the side combined with diffuser ramp angles. The ride heights of models with diffusers of other automotive shapes have also been investigated. ${ }^{26,27} \operatorname{Cooper}^{27}$ also looked at the effect of fixed and moving floors on the performance of diffuser. The more complex geometry of a Formula 3 car diffuser has been studied by Peddie. ${ }^{28}$ Jens $^{29}$ has used a response surface approach for optimisation of a diffuser in supersonic flow.

In this work, we concentrate on the interaction between the parameters of ride height and ramp angle. We follow the work of Senior ${ }^{20}$ and use the same inverted Ahmed model for its simple geometry. The slanted edge is lowermost and closest to the ground to represent a simplified 
diffuser as pictured in Figure 1a. We use the same analysis approach used by Ruhrman ${ }^{22}$ in this work for a long diffuser. However, we follow the response surface approach used by Jens ${ }^{29}$ to study the short diffuser. A schematic of our approach is shown in Figure 1b detailing the parameters used.

We initially report wind tunnel setup and results which have been used to validate the CFD models without the ground. Thereafter the ground is added to the CFD model and the methodologies used are described. The CFD simulation for the long diffuser was achieved using Star CCM+ with a matrix of ride heights and diffuser ratios investigated. The short diffuser simulations have been achieved using Ansys ${ }^{\circledR}$ Fluent with the optimization tool. The relationship between the model ride height and diffuser ramp angles on generated downforce and efficiencies are presented for the long and short diffuser of $35 \%$ and $10 \%$ relative lengths respectively. Finally some comparisons are drawn and conclusions offered.

\section{Validation of Flow around Inverted Ahmed Model}

The open jet wind tunnel at the University of Hertfordshire has been used for obtaining pressure distribution along the centreline of the slanted surface side of the Ahmed body. The pressure measurements were obtained using a scani-valve connected to a digital manometer. The results from this are compared to the Computational Fluid Dynamies simulation to demonstrate eonfidence in the approaches reported later._The tunnel has a circular cross-section of $480 \mathrm{~mm}$ diameter. The speed of the wind tunnel was set at $20 \mathrm{~m} / \mathrm{s}$ and turbulence intensity measured at 1\%. These conditions are used as inlet boundary conditions in the CFD models approach. 
The Ahmed model used had a cross-sectional area of $0.029 \mathrm{~m}^{\wedge} 2(145 \mathrm{~mm}$ deep $\mathrm{x} 200 \mathrm{~mm}$ wide) resulting in a blockage ratio of $4 \%$. According to Barnard, a less than $5 \%$ blockage in an open jet tunnel is recommended to provide a realistic aerodynamic flow. A 5\% blockage would typically give accurate results to within 10\% difference in drag measurements. Due to thise relatively low blockage, no correction factors were applied and the difference accepted within the error estimate. Pressure tapings are located along the longitudinal centreline. The model is aligned with the flow and supported by overhead struts and a tailwire as pictured in Figure 1a.

The CFD approach used a velocity for the inlet and a pressure for the outlet boundary conditions respectively. A non-slip wall was used for the Ahmed model surface and slip wall conditions used for the remaining boundaries of the domain. The Navier-Stokes equations are solved using finite volume method within Star CCM+ and Fluent. In both approaches, the SIMPLE algorithm is used with Central differencing schemes for all the computations. $\underline{\text { Convergence is obtained for all simulations with criteria set at a minimum } 0.001 \text { in all }}$ dependant variables reported in this work.

The CFD simulation has been setup to provide an aceurate-solution to within $\underline{10} 5 \%$ of the experiment. Much improved accuracy can be obtained by increasing the resolution of the mesh but at the expense of computational time. The reduced accuracy enables an increased number of simulations to find the optimum parameters of the diffuser for a given timeframe. Both Fluent 
and Star $\mathrm{CCM}+$ were used in the validation of the Ahmed model in freestream air. In all cases longitudinal centreline. The results from Fluent and Star CCM+ were found to be within 1\% difference in pressure coefficient, $\mathrm{Cp}$, so only the Fluent results are reported here.

The standard k-epsilon turbulence model has been widely used and validated in literature. In addition we use the k- $\omega$ SST turbulence model in our validation. Both models are 2 equation models and provide a solution to the RANS with a reasonable degree of accuracy at a reasonable computational expense. The use of more accurate models such as DES and LES would require much increased computational power and is beyond scope of the current work. Figure 2 shows the velocity magnitude contour plot of the inverted Ahmed model using the k- $\omega$ SST turbulence model. The inset in Figure 2 shows a zoomed in section at the rear of the model showing the separated shear layers from top and bottom surfaces.

The pressure distributions from the wind tunnel measurements and the k- $\omega$ SST and the standard k-epsilon turbulence models ${ }^{30}$ are shown in Figure 3. The distribution of pressure taps along the chord line of the upside down Ahmed body can also be seen in Figure 3 as discrete data points. The pressure distribution has been non-dimensionalised to obtain the pressure coefficient, $\mathrm{Cp}$. 
Good agreement can be seen over most of the lower surface of the model. Notable differences

Both the experimental and computational approaches contain errors. A high quality experiment using sensitive equipment and accounting for blockage compared with a high fidelity CFD $\underline{\text { simulation would improve the accuracies and correlation between approaches. However, in this }}$ work with a large number of simulations, we concentrate on identifying the trends and accept the inaccuracies, which are estimated to be within $10 \%$ between approaches. The comparison of 
pressure distributions are presented here merely to demonstrate confidence in the CFD approaches.

\section{Computational Methodologies used for Inverted Ahmed Model in ground effect}

The diffuser geometries being investigated were of 0.65 and 0.9 diffuser ratios, meaning that diffuser starts at $65 \%$ and $90 \%$ respectively of the length of the model. Its size is therefore $35 \%$ and $10 \%$ respectively of the length of the model. We name the $35 \%$ relative length diffuser as the long diffuser and the $10 \%$ relative length diffuser as the short diffuser.

The ground was added to the CFD models used in the validation. The boundary condition applied at the ground was set to slip wall conditions to model the road or moving floor. A polyhedral mesh was used for the long diffuser. The mesh base size used was $0.13 \mathrm{~m}$ with the model minimum and target mesh sizes being $5 \%$ and $10 \%$ of the base size, respectively. With this mesh a good mix of accuracy and computing time was achieved to facilitate a large number of simulations within a given timeframe. However, for low ride height values the mesh had to be refined to produce sensible values and achieve convergence, which resulted in longer computing times. The long diffuser allowed for experimentation with different diffuser ramp angles up to a maximum of $38.5^{\circ}$ which would result in a sharp trailing edge of the Ahmed model. The angles investigated were chosen to be $35^{\circ}, 30^{\circ}, 25^{\circ}, 20^{\circ}, 15^{\circ}, 10^{\circ}$ and $5^{\circ}$. The ride heights were chosen to be $50,40,30,20,10$ and $5 \mathrm{~mm}$. The lowest ride height being $5 \mathrm{~mm}$ off the ground was added to study the area where the ground effect has the most significant 
influence and to ensure a maximum point was reached in the results presented later. All 6 ride heights were simulated with all 7 angles, resulting in 42 simulation runs.

Fluent has been used to investigate the short diffuser using a similar approach to that used when investigating the long diffuser. However, the mesh has been defined as the default tetrahedrons with refining box of influence and inflation of prismatic layers on the walls. In addition, a different analytical approach to finding the optimum values has been used, namely, the Ansys Response Surface Optimization tool. ${ }^{31}$ For this purpose the two input parameters of ride height and diffuser ramp angle have been defined in the Design Modeller. Four output parameters have been monitored which were, Number of Mesh elements and Mesh Skewness for purpose of validity of the solution and Coefficient of Lift and Drag for optimization. ${ }^{31}$ Based on a reduced number of simulations compared to the long diffuser case, a response surface has been created, which determines the probability of occurrence of the desired solutions. From this assumption the optimization has been performed for maximising downforce coefficient, $-\mathrm{Cl}$ and maximising downforce efficiency, $-\mathrm{Cl} / \mathrm{Cd}$. Results from the optimization have been verified, which has created additional simulation points for a new response surface. This closed loop procedure has been repeated until the solution has been satisfied. ${ }^{31}$ In all cases convergence was obtained. A typical mesh of the short diffuser is shown in Figure 4.

\section{Results}

Figure 5 shows the change in downforce, $-\mathrm{Cl}$, for various ramp angles and ride heights of the long diffuser. As the long diffuser model approaches the ground it experiences an increase in 
downforce for all ramp angles except $35^{\circ}$. The $35^{\circ}$ diffuser shows very little change over with reached. All diffuser ramp angles show a reduction in downforce at the closest point to the ground as can be seen in Figure 5. At $20 \mathrm{~mm}$ ride height the maximum downforce coefficient is 1.43 and was produced by $25^{\circ}$ diffuser ramp angle, whereas at $10 \mathrm{~mm}$ ride height the maximum downforce is 1.41 but was produced by the $20^{\circ}$ ramp angle (see Figure 5). $5^{\circ}$ and $10^{\circ}$ diffuser ramp angles produced the least downforce in general, although, interestingly, at $10 \mathrm{~mm}$ ride height, the $10^{\circ}$ diffuser ramp angle produced more downforce than $30^{\circ}$ and $35^{\circ}$ diffuser ramp angle arrangements. At this ride height the $10^{\circ}$ diffuser is near its optimum, whereas the $30^{\circ}$ diffuser is too close to the ground to work efficiently and the $35^{\circ}$ diffuser does not work efficiently at any angle. At the lowest ride height tested of $5 \mathrm{~mm}$, the optimum diffuser ramp angle is shown to be $10^{\circ}$ in Figure 5. At this ride height none of the diffusers are working efficiently, but the $10^{\circ}$ diffuser is shown to give most downforce.

The peaks of maximum downforce were found at $10 \mathrm{~mm}$ ride height for diffusers with $20^{\circ}, 15^{\circ}$, $10^{\circ}$ and $5^{\circ}$ ramp angles. $20 \mathrm{~mm}$ ground clearance was optimum for $25^{\circ}$ diffuser and $30 \mathrm{~mm}$ ground clearance for $30^{\circ}$ diffuser. This shows the optimum downforce is a combined function of ride height and ramp angle. Therefore, the $30^{\circ}$ ramp angle diffuser is best for ride height of $30 \mathrm{~mm}$ and above, the $25^{\circ}$ ramp angle diffuser for a ride height of $20 \mathrm{~mm}$ and the $20^{\circ}$ ramp angle diffuser is best for a ride height of $10 \mathrm{~mm}$. It should be noted more accurate results could be obtained refining the simulations or using polynomial functions. Nevertheless, a clear dependency between ramp angle and ride height on downforce generation is shown. 
Aerodynamic efficiency is a measure of downforce generation with respect to drag. Drag is an

The results from the short length diffuser optimisation study are shown in the Figure 7 . The contour plot of dependence of the diffuser parameters on the down force $(-\mathrm{Cl})$ as well as downforce efficiency (-Cl/Cd) are presented. The optimum ride height and diffuser angle for downforce generation has been determined as $12 \mathrm{~mm}$ and $10^{\circ}$ respectively. This corresponds to a maximum coefficient of lift of -0.625 . This is also very close to the most aerodynamically 
efficient point as well being at the same ramp angle but slightly higher ride height of $13 \mathrm{~mm}$, which corresponds to a ratio of $2.5 \%$ when compared with length of model. This suggests the

The downforce efficiencies for both long and short diffusers are shown in Figure 8 for varying ramp angles at 10 and $20 \mathrm{~mm}$ ride heights. These ride heights are in the region of optimal efficiency and allow a direct comparison between the short and long diffusers to be made. The trend in downforce is very similar to the trend downforce efficiency so only the downforce efficiency is reported here. As can be seen from Figure 8, the trends in downforce efficiencies do vary similarly with changes in ride height and ramp angle for the both the long and short diffusers. The comparison clearly shows the much larger downforce efficiency of the long diffuser as expected due to increased surface area. The long diffuser achieves these higher efficiencies at higher angles when compared to the short diffuser. Conversely, the short diffuser has lower maximum efficiencies at lower angles when compared to the long diffuser. The profile of efficiencies in the short diffuser can also be seen in Figure 8 to be flatter, which suggests lower sensitivities for shorter diffusers.

\section{Conclusions}

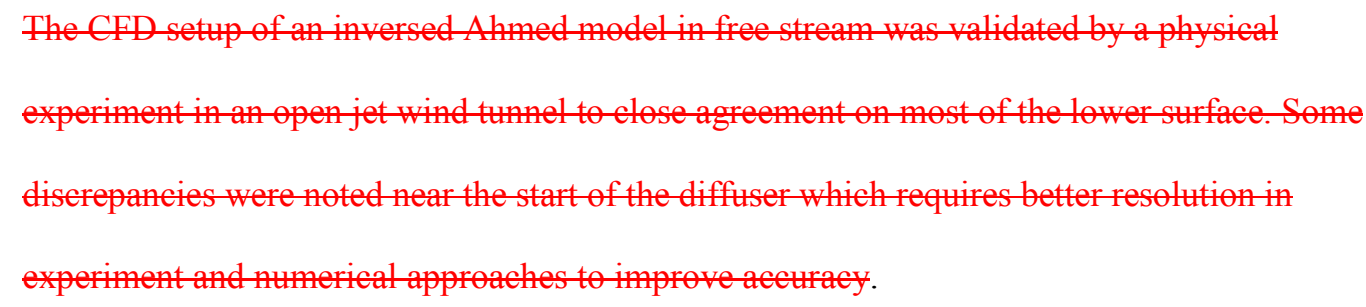


Downforce values and efficiency were obtained for multiple ride heights with different diffuser ramp angles for a long and a short diffuser. Both diffusers show similar trends to changes in ride height and ramp angle but at different absolute values.

The most efficient arrangements for the long diffuser ratio were found to be in close proximity over a relatively large variation in ride height. Awithin $1 \%$ difference in efficiency was noted using 10 to $30 \mathrm{~mm}$ ride heights. However, the higher the ride height, the higher the ramp angle needed to maintain optimal efficiency. At $10 \mathrm{~mm}$ ride height a $19^{\circ}$ diffuser ramp angle was optimum, whereas at $20 \mathrm{~mm}$ and $30 \mathrm{~mm}$ ride heights, $24^{\circ}$ and $27^{\circ}$ ramp angles respectively wasere found to be the most efficient. Thence, the higher the ride height, the higher the ramp angle needed to maintain optimal efficiency. The most efficient arrangement overall for the Ahmed Model with long diffuser of $35 \%$ relative length diffuser was found to have a downforce/drag ratio of 3.03 at $20 \mathrm{~mm}$ ride height with $25^{\circ}$ diffuser ramp angle in $20 \mathrm{~m} / \mathrm{s}$ air speed. The $20 \mathrm{~mm}$ ride height corresponds to a ratio of $3.8 \%$ when compared with length of model.

The short diffuser model produced much lower values of downforce and efficiency values as expected from reduced area of the diffuser. The short diffuser was found to be more sensitive in the productedion of highest downforce and bestefficiency. For the same $1 \%$ difference in maximum efficiency a much smaller range of ride heights was observed. At $11 \mathrm{~mm}$ ride height a $\underline{9^{\circ} \text { diffuser ramp angle was optimum, whereas at } 14 \mathrm{~mm} \text { ride height, } 11^{\circ} \text { ramp angle was found }}$ 
to be the most efficient. at a ramp angle of 10 degrees. The most downforce was obtained with ride height ratio of $12 \mathrm{~mm}$ which corresponds to a ratio of $2.1 \%$ when compared with length of model. The most efficient production of downforce in the short diffuser was again at 10 degrees but at a slightly increased ride height ratio of $2.5 \%$.

The optimum downforce and efficiency for long diffusers was found to be more sensitive, larger and occurring at higher ride heights and angles, when compared to the short diffuser. The short diffuser was found to be more sensitive. Different ride heights correspond to different diffuser angles for optimum downforce and efficiency in both the long and short diffusers.

\section{Acknowledgments}

The authors would like to acknowledge the use of the University of Hertfordshire wind tunnel, Star CCM+ and ANSYS FLUENT CFD software used in this work.

\section{References}

1. Katz J. New Directions in Race Car Aerodynamics: Designing for Speed. 2nd ed. 2008.

2. Zhang X et al. Ground Effect Aerodynamics of Race Cars. Applied Mechanics Reviews 2006; 59(1): 33.

3. Bansal R and Sharma RB. Drag Reduction of Passenger Car Using Add-On Devices. Journal of Aerodynamics 2014: 1-13.

4. Loftus D, Found MS and Yates JR. The performance of aluminium to carbon fibre composite bonded joints in motorsport applications. Sports Engineering 2002; 2(4):

201-257. 
5. Graham T. Surface coatings offer opportunities for protection in harsh environments. In: Transactions of the IMF; 89, Issue 2 (March 2011), pp. 71-72.

6. Jawaid M and Abdul Khalil HPS. Cellulosic/synthetic fibre reinforced polymer hybrid composites: A review. Carbohydrate Polymers 2011; 86: 1- 18.

7. Pil L, Bensadoun P, Parisent $J$ and Verpoest I. Why are designers fascinated by flax and hemp fibre composites. Composites: Part A 2016; 83: 193-205.

8. Hucho WH. Aerodynamics of road vehicles. $4^{\text {th }}$ ed. Warrendale, Pennsylvania: SAE International. 1998.

9. Barnard RH. Road vehicle aerodynamics. 3rd ed. Mechaero Publishing, 2010.

10. Huminic A et al. Study of aerodynamics for a simplified car model with the underbody shaped as a Venturi nozzle. International Journal of Vehicle Design 2012; 58(1): 15-32.

11. White FM. Fluid Mechanics. New York: McGraw-Hill Print, 1986.

12. Baxendale, A. J., Graysmith, J. L., Howell, J. P., and Haynes, T. Comparisons between CFD and experimental results for the Ahmed reference model. In Proceedings of the Royal Aeronautical Society Conference on Vehicle Aerodynamics, London, UK, 18-19 July 1994, pp. 30.1-30.11.

13. Han T. Computational analysis of three-dimensional turbulent flow around a bluff body in ground proximity. AIAA Journal 1989; 27 (9): 1213-1219.

14. Chee Chok SC, Parameswaran RS, Sun MR and Gleason M. Numerical investigation of the effects of base slant on the wake pattern and drag of threedimensional bluff bodies with a rear blunt end. Journal of Wind Engineering and Industrial Aerodynamics 1994; 51, 269-285.

15. Tunay T, Sahin B and Akilli H. Experimental and numerical studies of the flow around the Ahmed body. Wind and Structures 2013; 17: 515-535.

16. Yakhot V, Orszag SA, Thangam S et al. Development of turbulence models for shear flows by a double expansion technique. Phys. Fluids A 1992; 4(7): 1510-1520. 
17. Serre E, Minguez M, Pasquetti R, et al. On simulating the turbulent flow around the Ahmed body: A French-German collaborative evaluation of LES and DES. Computers \& Fluids 2013; 78: 10-23.

18. Minguez M, Pasquetti R and Serre E. High-order large-eddy simulation of flow over the "Ahmed body" car model. Physics of Fluids 2008; 20, 095101.

19. Howard RJA and Pourquie M. Large eddy simulation of an Ahmed reference model. Journal of Turbulence 2002; 3, N12.

20. Senior AE and Zhang X. The Force and Pressure of a Diffuser-Equipped Bluff Body in Ground Effect. Journal of Fluids Engineering 2000; 123(1): 105-111.

21. Puglisevich LS and Page G. Large Eddy Simulation of the Flow Around a DiffuserEquipped Bluff Body in Ground Effect. In: ASME International Mechanical Engineering Congress and Exposition, 2011. ASME.

22. Ruhrmann A and Zhang X. Influence of Diffuser Angle on a Bluff Body in Ground Effect. Journal of Fluids Engineering 2003; 125(2): 332-338.

23. Huminic A and Huminic G. Computational Study of Flow in the Underbody Diffuser for a Simplified Car Model. SAE Technical Paper 2010-01-0119, 2010.

24. Han T. Computational analysis of three-dimensional turbulent flow around a bluff body in ground proximity. AIAA Journal 1989; 27(9): 1213-1219.

25. Han T, Hammond DC and Sagi CJ. Optimization of bluff body for minimum drag in ground proximity. AIAA Journal 1992; 30 (4): 882-889.

26. Desai S, Lo C and George A. A Computational Study of Idealized Bluff Bodies, Wheels, and Vortex Structures in Ground Effect. SAE Technical Paper 2008-01-0327, 2008 .

27. Cooper K, Bertenyi T, Dutil G, Syms J et al. The Aerodynamic Performance of Automotive Underbody Diffusers. SAE Technical Paper 980030, 1998.

28. Peddie KM and Gonzalez LF. CFD Analysis of the Diffuser of a Formula 3 Racecar. Orbit: University of Sydney Undergraduate Research Journal 2009; 1(1). 
29. Jens I, Madsen, Shyy W and Raphael TH. Response Surface Techniques for Diffuser Shape Optimization. AIAA Journal 2000; 38(9): 1512-1518.

30. Jones WP and Launder BE. The prediction of relaminarization with a two-equation model of turbulence. Int. J. Heat Mass Transfer 1972; 15: 301-314.

31. ANSYS Inc. ANSYS 14.5 Help. ANSYS, Inc. Theory Release 8. 2012.

\section{Figure Captions}

Figure 1 Inverted Ahmed model located in open jet wind tunnel a) picture b) schematic. Figure 2 Contour Velocity plot using is k- $\omega$ SST turbulence model.

Figure 3 Pressure distribution along the longitudinal centreline of Ahmed body.

Figure 4 Detailed mesh example.

Figure 5 Line plot of downforce (-Cl) against ride height for various ramp angles of long diffuser.

Figure 6. Line plot efficiency ratio $(-\mathrm{Cl} / \mathrm{Cd})$ against ramp angle for various ride heights of long diffuser.

Figure 7 Contour plot of downforce and efficiency optimization of short diffuser.

Figure 8 Line plot of downforce efficiency $(-\mathrm{Cl} / \mathrm{Cd})$ for long and short diffusers at $10 \mathrm{~mm}$ and $20 \mathrm{~mm}$ ride heights. 


\section{Page 19 of 25 \\ Journal of Automobile Engineering}
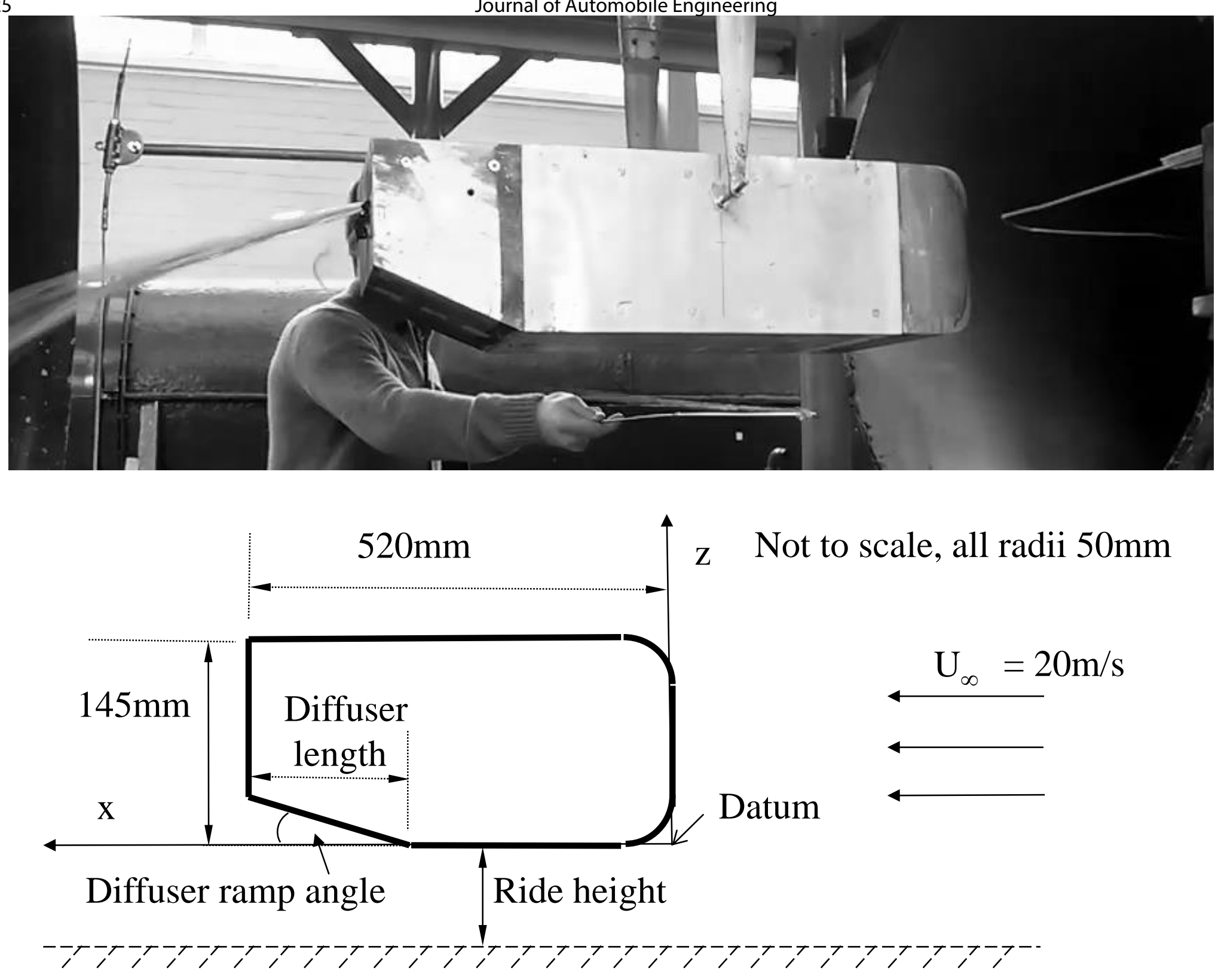

Ground not present in experiment http://mc.manuscriptcentral.com/sauto 


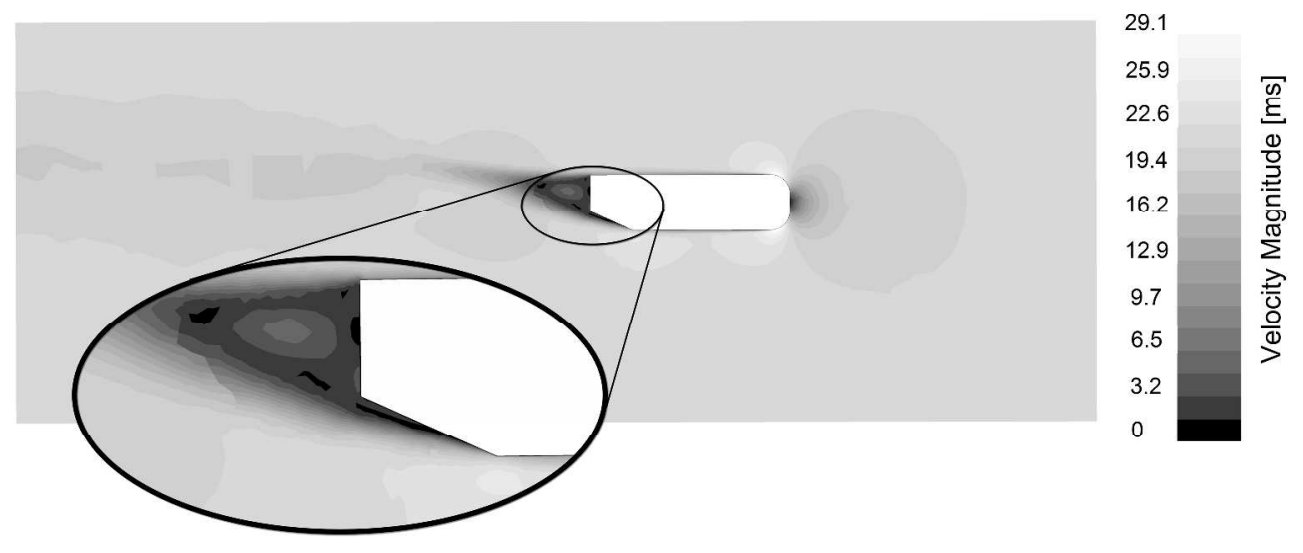

Figure 2 Contour Velocity plot using is k- $\omega$ SST turbulence model.

$2016 \times 867 \mathrm{~mm}(96 \times 96$ DPI) 


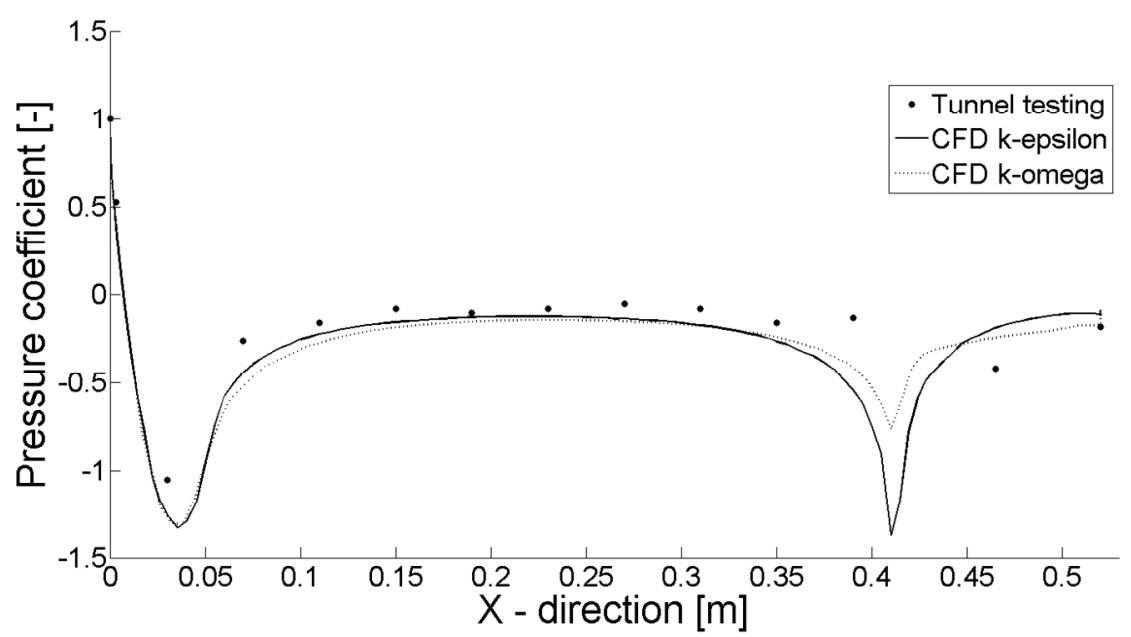

Figure 3 Pressure distribution along the longitudinal centreline of Ahmed body. $423 \times 211 \mathrm{~mm}(96 \times 96 \mathrm{DPI})$ 


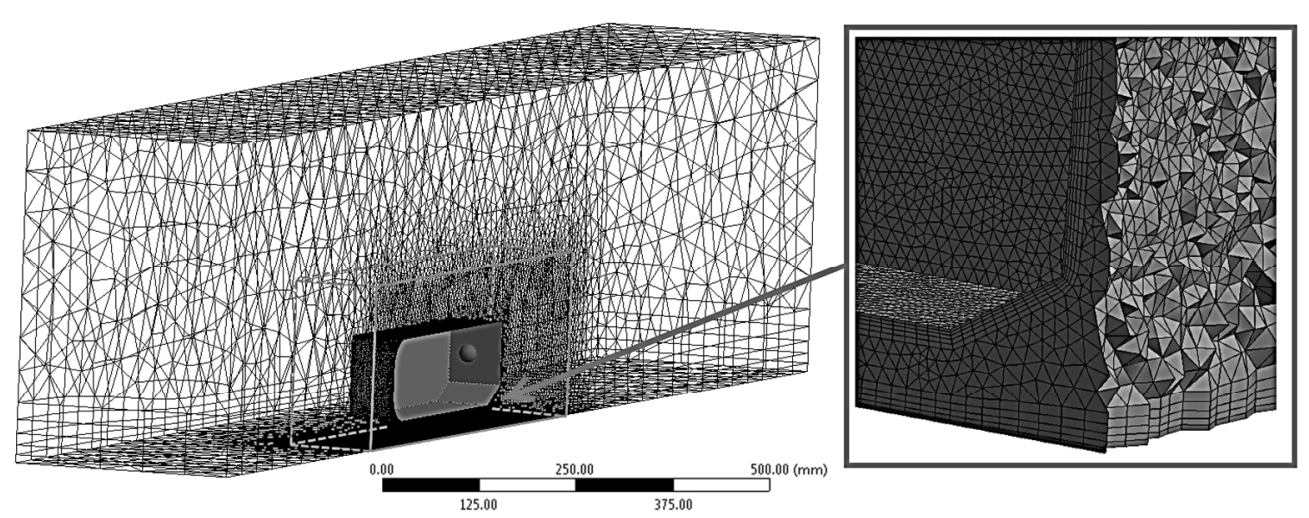

Figure 4 Detailed mesh example.

$399 \times 153 \mathrm{~mm}(96 \times 96$ DPI) 


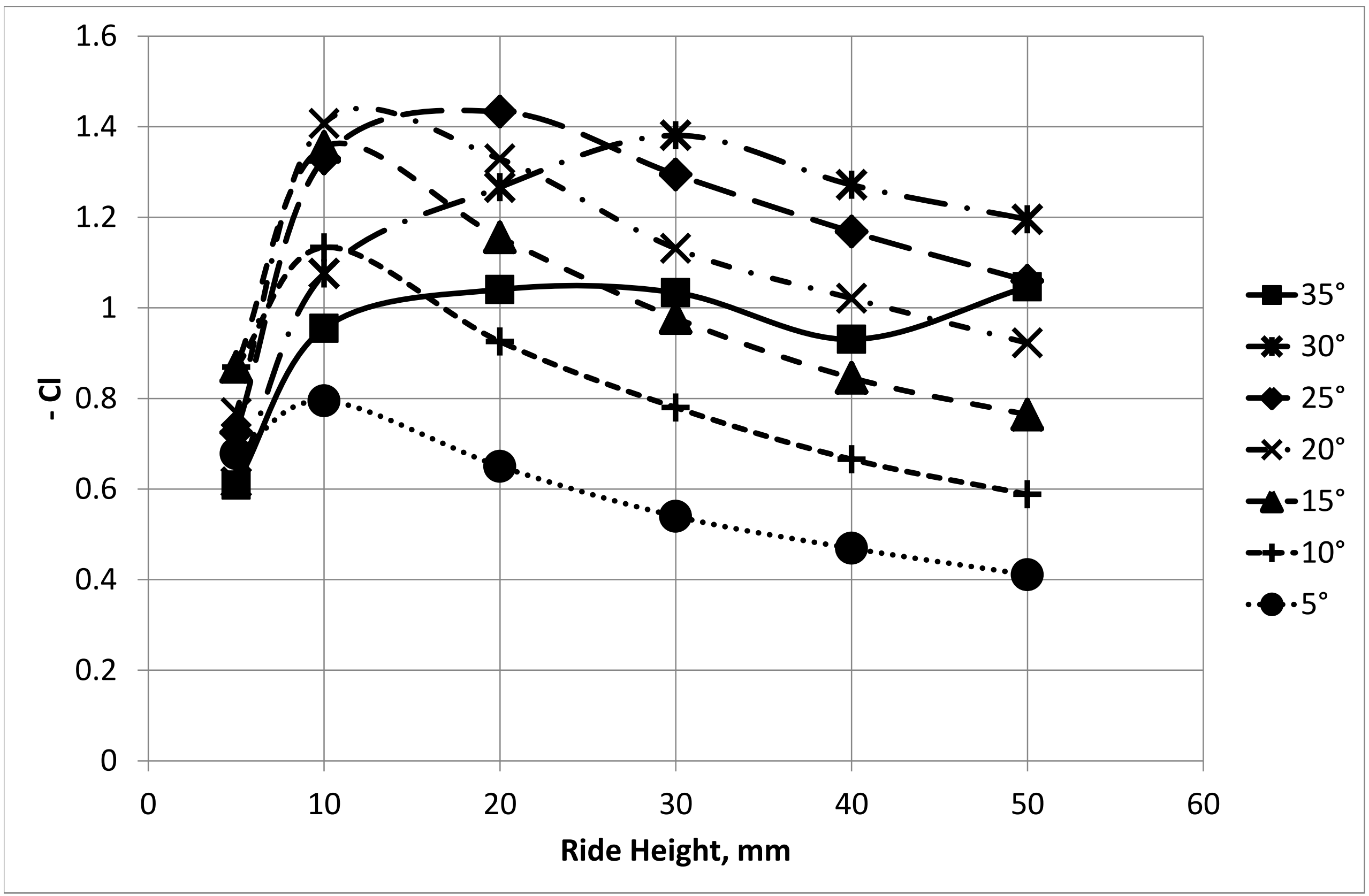




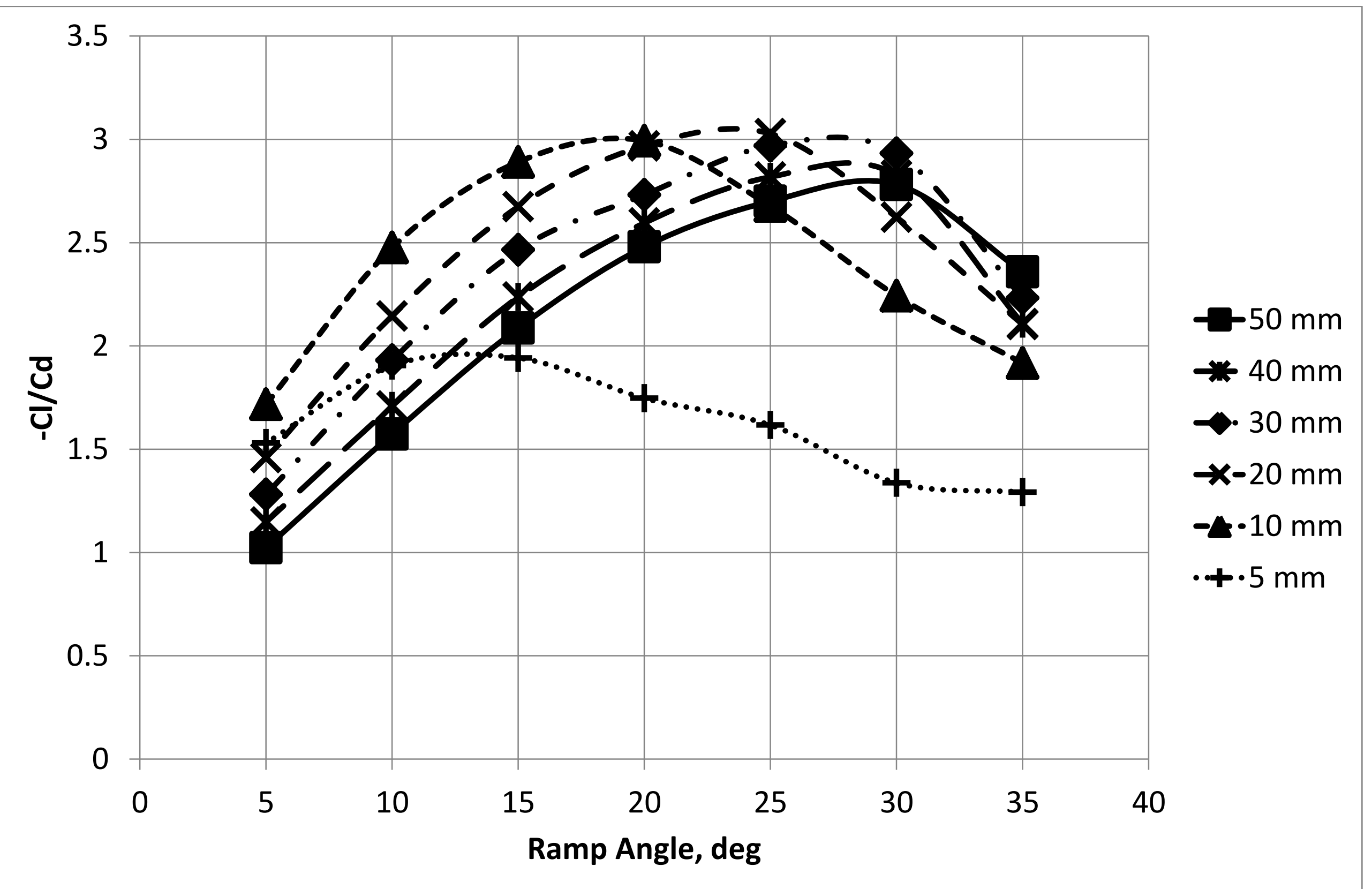



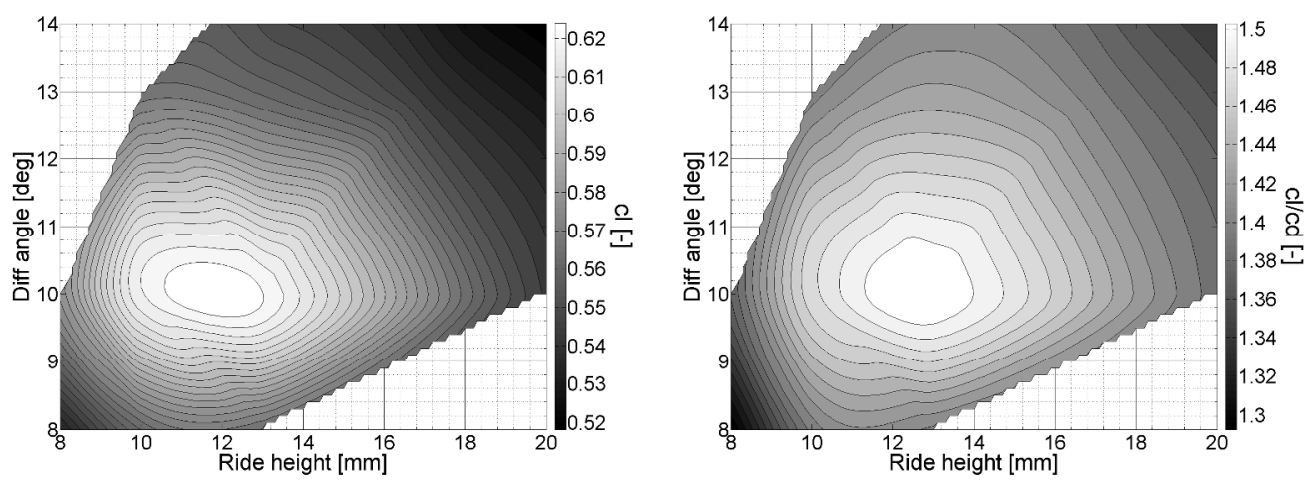

Figure 7 Contour plot of downforce and efficiency optimization of short diffuser.

$830 \times 317 \mathrm{~mm}(96 \times 96 \mathrm{DPI})$ 


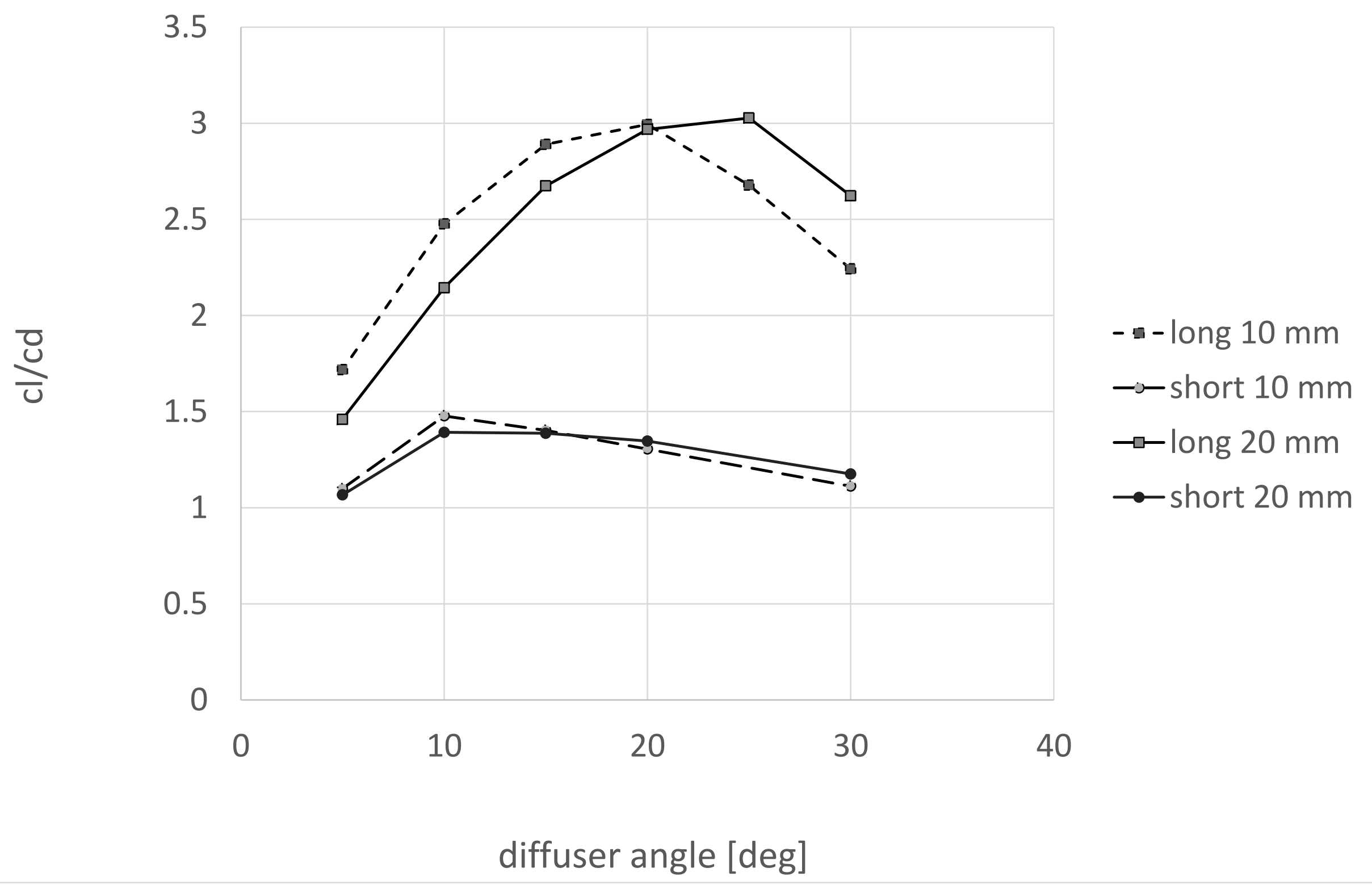

http://mc.manuscriptcentral.com/jauto 